\title{
ASPECTOS ESTRUTURAIS DA VIOLÊNCIA NO CAMPO: UMA REVISÃO BIBLIOGRÁFICA A PARTIR DO CASO BRASILEIRO
}

\author{
Juliana Maria Magalhães lopes Cerqueira \\ DENES DANTAS VIEIRA \\ Universidade Federal do Vale do São Francisco (UNIVASF), \\ Petrolina, Pernambuco, Brasil
}

Resumo: A história do campesinato brasileiro é marcada por episódios brutais de violência. De Canudos a Eldorado dos Carajás, a violência tem se constituído como um fenômeno presente no âmbito rural, atingindo altos índices em períodos determinados. Em 2016, dados revelaram um aumento da violência no campo no Brasil. Este artigo tem como objetivo investigar as raízes desta violência para compreender a elevação das estatísticas atualmente. O estudo consiste em uma revisão bibliográfica, baseada, sobretudo, em obras de estudiosos como José de Souza Martins (1990) e Leonildes Sérvulo de Medeiros (2002), com foco maior na trajetória de conflitos sociais das décadas de 1950 a 1990. Os resultados da pesquisa mostram que a violência é fruto da própria formação do campesinato brasileiro e reproduz praticamente as mesmas estruturas ao longo da formação política, econômica e social brasileira.

Palavras-chave: Campesinato. Violência no campo. Luta pela terra. Exclusão social. 


\section{INTRODUÇÃO}

Em 2017, Colniza (MT), Vilhena (RO), Pau D'Arco (PA) e Lençóis (BA), quatro municípios de regiões distintas e que não ultrapassam 100 mil habitantes cada um, ganharam as páginas e as telas do noticiário brasileiro, em razão da violência no campo. No município mato-grossense, nove posseiros foram assassinados por arma calibre 12 e golpes de facão; em Rondônia, a Liga dos Camponeses Pobres denunciou o assassinato de três trabalhadores que atuavam na luta pela reforma agrária; em Pau D'Arco, dez trabalhadores rurais sem terra, nove homens e uma mulher, foram mortos em uma ação das polícias militar e civil do Estado; na comunidade de lúna, na Bahia, seis quilombolas foram mortos a tiros dentro de suas residências. ${ }^{1}$

Estes não são os únicos casos de violência no campo em 2017, mas chamam a atenção pela barbaridade e pela quantidade de assassinatos e refletem as estatísticas do Brasil, muitas vezes, veladas na esfera pública. Dados do Caderno de conflitos no campo 2017, publicação da Comissão Pastoral da Terra (CPT) - que desde 1985 registra ocorrências de conflitos no campo no país -, mostram que 2017 foi o ano mais violento desde 2003. No ano passado, a entidade registrou 71 assassinatos no campo - 14\% a mais que em 2016 e 30\% em relação a 2015 - , 120 tentativas de assassinatos, 226 ameaças de morte, 137 pessoas agredidas e 263 presas em decorrência de conflitos no campo.

Diante dos acontecimentos e das estatísticas, percebe-se que há um crescente aumento da violência no campo brasileiro nos últimos anos. Violência esta entendida aqui como aquela que é fruto de conflitos desenvolvidos no âmbito rural, envolvendo diferentes atores sociais, como trabalhadores rurais, assentados, comunidades tradicionais, agricultores familiares, ribeirinhos e cujas motivações são a luta pela terra, por água, direitos e meios de produção. ${ }^{2}$ Casos de chacinas e massacres ganham repercussão e visibilidade nos diversos segmentos sociais, entretanto, a discussão sobre a violência no campo não deve ser restrita apenas a esses momentos, pois este é um problema histórico brasileiro, intrinsecamente relacionado aos processos de formação da nossa sociedade.

Este trabalho tem como objetivo investigar a história da violência no campo no Brasil e suas raízes, assim como identificar os períodos em que esse tipo de violência atingiu altos índices de crescimento e os diversos sujeitos sociais envolvidos nesses momentos. Busca-se também compreender quais são as motivações dessa violência. 
O estudo utiliza, principalmente, como metodologia a revisão bibliográfica, a partir de autores como Martins (1990) e Medeiros (2002). O artigo está estruturado em três seções. Primeiro, é apresentada a problemática da pesquisa. Em seguida, apresentamos os dados obtidos na revisão bibliográfica, que estão concentrados em três períodos históricos identificados como essenciais para o entendimento da violência no campo no país: os anos 1950, a ditadura militar e as décadas de 1980/90. Posteriormente, realizamos a análise desses dados e dialogamos com o contexto atual.

\section{Problemática de PESQUisa}

O campesinato brasileiro é plural e se manifesta de diversas formas entre seus agentes, a exemplo dos posseiros, dos assentados e dos povos tradicionais, que têm características e dinâmicas próprias. Não podemos tratar o campesinato como um fenômeno puro no Brasil, tampouco importar modelos, como o europeu, para suprir o entendimento dos processos e das relações sociais do campo brasileiro. Martins (1990) aponta que, diferente da realidade russa, o campesinato brasileiro é um campesinato de classe e não estamental e apresenta como produto um camponês desenraizado, migrante e itinerante. De acordo com o autor, o campesinato brasileiro é fruto da ação do capital:

Nosso campesinato é constituído com a expansão capitalista, como produto das contradições dessa expansão. Por isso, todas as ações e lutas camponesas recebem, de imediato, reações de classe: agressões e violências, ou tentativa de aliciamento, de acomodação, de subordinação. O direito da propriedade que, afinal de contas, o camponês invoca judicialmente para resistir às tentativas de expropriação é o mesmo direito que o capitalista invoca para expropriar o camponês. [...] É das contradições desse direito, que serve a duas formas de propriedade privada - a familiar e a capitalista - que nascem as interpretações distintas sobre a terra camponesa e a terra capitalista, terra de trabalho e terra de negócio (MARTINS, 1990, p. 16, grifos do autor).

Portanto, em decorrência da formação do nosso campesinato, a violência se constituiu presente, desde o início, como parte dessa história. $E$, se entendemos o campesinato como classe, é necessário compreender o espaço que ele ocupa e ocupou na história brasileira: o lugar da exclusão. Como afirma Martins (1990, p. 25), o camponês brasileiro "não é de fora, mas também não é de dentro", ele é um excluído dos processos políticos, econômicos e sociais. Essa exclusão vem se reproduzindo ao longo do tempo, repercutindo e se manifestando em diversas áreas e esferas sociais, a exemplo da mídia, da educação, das políticas públicas e da historiografia. 
Desde a colonização, com o regime escravista, à instauração das repúblicas, do golpe militar até a contemporaneidade, o campesinato no Brasil vem sendo alvo de violência, que assume distintos contornos, de acordo com a localidade e o período histórico. No final do século XIX, o povoado de Belo Monte, no sertão da Bahia, liderado por Antônio Conselheiro, foi dizimado por metade da força do exército brasileiro. Assim como o arraial de Canudos, a população do Contestado, no Sul do país, também foi devastada pelas forças militares. Na década de 1930, durante o governo Vargas, a comunidade de Pau de Colher foi palco de um massacre de cerca de mil pessoas pela força militar de Pernambuco. Todos esses episódios aconteceram no campo, em um país essencialmente rural, mas que já demonstrava a imediata reação violenta de classe à insurreição popular camponesa.

Quais são as consequências desses acontecimentos na história recente do campesinato brasileiro? Quais aspectos sociais desses momentos predominam até hoje no campo? Quais semelhanças existem entre a violência no campo hoje e naquele período? Estas são questões que nos norteiam e que apontam na direção de que só conseguiremos compreender o aumento recente da violência no campo se conhecermos as raízes desse problema e o papel que ela ocupa nas relações e nos processos no âmbito rural. Para Martins (1990, p. 16), "o campesinato não é uma figura do passado, mas uma figura do presente da história capitalista do país". Esse passado, segundo o autor, só pode ser compreendido por meio das relações de violência do capital e do Estado.

O presente estudo tem como abordagem metodológica a revisão bibliográfica. Esse instrumento metodológico busca construir o estado da arte sobre determinado tema, partindo de pesquisas já desenvolvidas, e contribuindo para a confirmação de hipóteses e a ampliação de conhecimentos teóricos (FROHLICH; FROHLICH, 2014). Ressaltamos que esta pesquisa não tem o intuito de suprir todas as lacunas a respeito do objeto pesquisado, mas de fazer o resgate histórico da violência no campo no Brasil, a partir de momentos-chave dessa história. O recorte temporal da investigação se deu durante o curso da pesquisa. A escolha por esses períodos foi em decorrência de acontecimentos, emergência de categorias, estruturas políticas, entre outros fatores, que impactaram diretamente o campesinato brasileiro e tiveram como consequência também altos índices de violência no campo. Entendemos a importância e a relevância dos acontecimentos anteriores ao corpus do estudo, entretanto, o recorte escolhido se justifica por fazer parte da história recente do país. 
Nos anos 1950, com o surgimento das Ligas Camponesas, o campesinato brasileiro se afirmou como categoria e identidade política. Com o golpe militar de 1964, uma série de mecanismos, inclusive jurídicos, como o Estatuto da Terra, impactou a vida do camponês. Também nesse período a chamada "Revolução Verde" introduziu a industrialização agrícola e desencadeou uma série de conflitos no campo. Na década de 1980, a ditadura militar chega ao fim e, no âmbito do campesinato, emerge a figura do assentado e a reforma agrária ganha visibilidade através das ocupações e das reivindicações pautadas na função social da terra. Acreditamos que esses três períodos são fundamentais para compreender as nuances da violência no campo no Brasil hoje.

\section{VIOLÊNCIA NO CAMPO BRASILEIRO}

O campesinato em nosso país atravessou diversas fases desde a sua constituição, cada uma com características e elementos diferenciados, moldadas a partir dos contextos políticos e econômicos da época. No Brasil colonial, marcado pela escravidão, o campesinato era formado pelas populações excluídas socialmente. Além do escravo, existiam outros grupos desfavorecidos e às margens da elite colonial: o indígena, o mestiço - filhos bastardos dos portugueses - e os excluídos dos morgadios. À exceção dos escravos, os demais pares faziam parte dos "agregados das fazendas", população que mantinha uma relação diferenciada da do escravo com o proprietário da terra, baseada na troca de serviços, produtos e favores (MARTINS, 1990).

Junto aos agregados, compunham a classe do campesinato as figuras dos posseiros e dos sitiantes, ambos responsáveis pela produção interna de alimentos e excluídos das estruturas do poder político e econômico. Martins (1990, p. 38) afirma que o camponês era "duplamente excluído: da condição de proprietário de terras e da condição de escravo, já que não podia ser convertido em renda capitalizada do tráfico colonial". O autor aponta que, nesse período, o campesinato é determinado pelo trabalho escravo:

O tráfico negreiro e o trabalho escravo eram exatamente os fatores que retiravam da colônia qualquer caráter feudal. Permitiam que, ao invés da metrópole tirar renda da terra através de uma elite territorial, de um monopólio de classe ou de um monopólio estritamente estamental sobre o solo, tirasse renda da circulação, fazendo o escravo produzir renda capitalista antes de produzir mercadorias (MARTINS, 1990, p. 37). 
A questão da terra, mais especificamente da propriedade do território, só se tornou fator preponderante no campesinato, segundo Martins (1990), com o fim do Império e o início da República. Com a promulgação da Lei de Terras em 1850, que instituiu o sistema privado de terras e transferiu aquelas "não ocupadas" para a tutela dos estados, e a abolição da escravatura, em 1888 , as dinâmicas sociais do campo ganharam novos contornos, entretanto, sem alterar as forças políticas e econômicas dos fazendeiros:

O senhor de escravos se transforma em senhor de terras. A terra que até então fora desdenhada em face da propriedade do escravo passa a constituir objeto de disputas amplas. A velha disputa colonial pela fazenda, pelos bens da família, transforma-se em disputa pela terra, pois essa é a forma de subjugar o trabalho livre (MARTINS, 1990, p. 45).

Essas disputas pelo território e a contestação do que ele representava desencadearam as primeiras grandes lutas camponesas que surgiram a partir desse período, a exemplo dos massacres de Canudos, no sertão baiano, e do Contestado, no sertão paranaense, quando mais da metade da força do exército brasileiro se deslocou a esses lugares. Durante a República Velha e a Era Vargas, três fenômenos caracterizaram o campesinato brasileiro: o messianismo, o cangaço e o coronelismo. Em todos estes, a violência constituiu-se como elemento crucial, seja na repressão, seja como produto de sua prática.

As primeiras formas de luta e resistência camponesas ocorreram já nesses primeiros anos de República, que foram também anos de intensas e generalizadas lutas de coronéis contra coronéis em todo o país, verdadeiras guerras [...]. As lutas camponesas dessa quadra são caracteristicamente constituídas pelos movimentos messiânicos [...] e pelo banditismo, especialmente configurado no cangaço (MARTINS, 1990, p. 49-50).

O foco deste artigo compreende o estudo dos períodos que sucederam o auge do coronelismo, do cangaço e do messianismo. Ainda que esses movimentos estivessem presentes nos anos seguintes encontramos influências e roupagens deles até na contemporaneidade -, outros atores sociais e políticas reconfiguraram o campesinato brasileiro nas últimas décadas. Com novas configurações, a violência no campo também passou a permear novos sujeitos e incorporou outras manifestações, como mostraremos nos itens a seguir. 


\subsection{DéCADA DE 1950: A EMERGÊNCIA DO CAMPESINATO COMO IDENTIDADE POLITICA}

As décadas de 1940 e 1950 foram marcadas por uma série de conflitos entre posseiros e fazendeiros em vários pontos do país, como Paraná, Minas Gerais, Goiás e Pernambuco. A ocorrência de despejos de camponeses de forma violenta, pelos fazendeiros, foi comum nesse período. A grilagem de terras, prática de falsificação de documentos de propriedades, despontou como instrumento de legalização dessas expulsões e de apropriação de territórios.

Em São Paulo, a crise da cafeicultura desencadeou a expulsão em massa dos colonos, que se tornaram trabalhadores volantes (boias-frias), temporários, operários e moradores de bairros pobres das cidades (MARTINS, 1990). Esse caso, segundo Martins (1990), não resultou em uma mobilização política dos camponeses, diferente do que aconteceu em outros lugares, principalmente, no Nordeste. Com a Segunda Guerra Mundial, o açúcar voltou a ser valorizado e os senhores de engenho retomaram o negócio da cana, que estava em crise. Entretanto, as terras das usinas estavam ocupadas por foreiros, que passaram a ser expulsos ou reduzidos à condição de assalariados.

No Engenho Galileia, em Pernambuco, surgiu, em 1955, a Sociedade Agrícola e Pecuária dos Plantadores de Pernambuco, uma associação de foreiros que logo se transformou em uma das maiores expressões da história do campesinato no Brasil, as Ligas Camponesas. Para Medeiros (2002), com as Ligas Camponesas em Pernambuco e na Paraíba, e a mediação do Partido Comunista Brasileiro (PCB) nessas lutas, o termo camponês constitui-se como uma identidade política.

[...] produziu uma nova linguagem, que expressava os conflitos localizados nos termos de transformações mais amplas que o país precisava passar. A partir daí, um conjunto de demandas esparsas, pontuais, localizadas, ganharam articulação (MEDEIROS, 2002, p. 158).

Essas demandas se afunilaram em uma bandeira unificada pela reforma agrária, que expressava também a condenação à concentração de terras e a sua improdutividade, o latifúndio (MEDEIROS, 2002). As outras demandas dos camponeses estavam relacionadas às condições de vida das populações rurais, como assistência à saúde e educação, e as de trabalho, numa perspectiva de extensão dos direitos dos trabalhadores da cidade para os do campo: 
Enquadrados pelo PCB nesse processo de mobilização e organização como assalariados, a demanda de uma parte significativa dos trabalhadores, principalmente os dos moradores de engenhos de açúcar e colonos das fazendas de café, foi a extensão da legislação trabalhista aos trabalhadores do campo, com a introdução do registro em carteira de trabalho, jornada de oito horas, repouso remunerado, férias, fim do desconto habitação (MEDEIROS, 2002, p.158, grifos da autora).

O PCB e as Ligas Camponesas constituíram-se como os principais atores de representação dos camponeses durante a década de 1950 e início dos anos 1960, embora apresentassem diferenças nas propostas políticas. "As Ligas dirigiam-se para uma proposta de revolução camponesa, enquanto que a estratégia do Partido Comunista caminhava na direção de uma coexistência pacífica com a burguesia", destaca Martins (1990, p. 78). A Igreja Católica também desponta como uma instituição de grande influência nesse processo, primeiro em oposição às lutas camponesas, posteriormente, estimulando a sindicalização - ainda ilegal para os trabalhadores rurais - e disputando as bases do PCB e das Ligas (MEDEIROS, 1990, p. 160).

Os anos que antecederam o golpe militar de 1964 foram assinalados pelo reconhecimento legal de algumas demandas da população do campo, como a regulamentação do sindicalismo rural e a aprovação do Estatuto do Trabalhador Rural. O golpe militar apresenta relações com os conflitos do campo, como ressalta Martins (1990), ao relatar o confronto de Governador Valadares, que abriu precedentes para que as tropas do exército avançassem no Rio de Janeiro. Medeiros (2002) também concorda que as reivindicações pela reforma agrária tiveram papel importante no desencadeamento do golpe.

Para Medeiros (2002), durante esse período dos anos 1950 até a ditadura, os trabalhadores do campo constituíram-se como força no debate político, munidos de demandas próprias e capazes de provocar mudanças significativas, como a obtenção de alguns respaldos legais. Entretanto, na prática, as vitórias legais não foram suficientes para assegurar direitos nos anos seguintes.

\subsection{DitAduRA MILITAR E "MODERNIZAÇÃO" DA AGRICULTURA}

Com a repressão do regime militar, lideranças camponesas foram assassinadas, presas e passaram a viver na clandestinidade, o que fez com que vários segmentos de trabalhadores rurais abandonassem o campo e fossem buscar formas alternativas de sustento nas periferias das cidades ou nos trabalhos agrícolas temporários (MEDEIROS, 2002). Outra ação promovida 
pela ditadura, que na verdade se tornou uma política, que contribuiu para essa evasão foi a chamada "modernização da agricultura". Apesar de ser discutida desde a segunda metade do século XIX, a modernização, que tinha como objetivo se opor à "agricultura e [a suas] práticas tradicionais", ganhou força na década de 1970 (HEREDIA; LEITE; PALMEIRA, 2010, p.159).

Essa política "modernizadora" estava incluída no grande bojo da proposta de desenvolvimento rural, que se estendia também a uma série de procedimentos legais, como o pagamento das desapropriações de terras com títulos de dívidas públicas e a aprovação do Estatuto da Terra, que definiu termos como latifúndio e minifúndio, estabelecendo o cumprimento da função social da terra (MEDEIROS, 2015). A industrialização e a modernização do campo acarretaram a intensificação dos conflitos nas áreas rurais, uma vez que consistiram na expansão de novas fronteiras, na Amazônia e no Cerrado, já ocupadas por posseiros e indígenas.

Nem o direito tradicional de usocapião conseguiu se impor, nem os trabaIhadores conseguiram, a partir das recorrentes mas atomizadas ações de resistência e denúncias da Contag, fazer valer o Estatuto da Terra, quer através das suas cláusulas que previam desapropriação das áreas de conflitos, desde que estas se caracterizassem como latifúndio, quer através das disposições que regulamentavam o arrendamento e parceria (MEDEIROS, 2002, p.162).

Heredia, Leite e Palmeira (2010) destacam a intervenção do Estado no processo de transformação do campo, a partir dos anos 1970, com a industrialização rural e que, posteriormente, resultou no que caracterizamos hoje como agronegócio. "Não se pode falar do agronegócio sem pensar no Estado e nas políticas públicas, que não só viabilizam sua origem mas também a sua expansão" (HEREDIA; LEITE; PALMEIRA, 2010, p.165). Através de incentivos e investimentos, o Estado atraiu para o campo grandes grupos empresariais multinacionais, responsáveis por realizar a introdução tecnológica no Brasil rural.

O sindicalismo e a Igreja Católica também marcaram presença muito forte nesse período junto aos camponeses. O primeiro, apesar de fragilizado, funcionava como difusor dos direitos sociais. Porém, os sindicatos eram reconhecidos como "instâncias de recebimento de benefícios", através da oferta de serviços médicos e odontológicos, e não como locais de organização e lutas (MEDEIROS, 2002, p. 163). Já segmentos da Igreja Católica, ligados à Teologia da Libertação, passaram a realizar trabalhos pastorais em comunidades eclesiais de base, atualizando a leitura bíblica na luta pela terra, "que deu as bases religiosas para a legitimação de novas formas de ação coletiva, garantindo a afirmação e legitimação de um novo repertório de 
ação, baseado nas ocupações de terra" (MEDEIROS, 2015, p. 345). Essa atuação da Igreja resultou na criação da Comissão Pastoral da Terra em 1975, que tem como finalidade o apoio à luta camponesa, e na crítica do sindicalismo assistencialista da época. No final dos anos 1970, a figura do "sem-terra" surge como novo ator na luta pela terra (MEDEIROS, 2015). Esse sujeito tinha como principal ação de reivindicação a ocupação, prática que ganhou visibilidade e força política nos anos seguintes.

\subsection{REABERTURA DEMOCRÁTICA E SIMBOLOGIA DAS OCUPAÇÕES}

Na década de 1980, no Brasil, aconteceram grandes mudanças no cenário nacional. No plano político, a ditadura militar chega ao fim e há uma gradual retomada democrática. Com a Nova República, a discussão sobre a ampliação e a garantia dos direitos sociais ganha força e se consolida com a Constituição cidadã de 1988. No campo, acontece um momento de renovação de lutas, estratégias e reivindicações. Para Medeiros (2002), nessa década, iniciou-se um novo ciclo de lutas, a partir dos efeitos da modernização da agricultura, como a construção de hidrelétricas e a emergência de novas categorias como o "sem-terra", o "seringueiro", o "atingindo". Esses novos atores se somaram às categorias anteriores, mesmo apresentando reflexões e dinâmicas diferenciadas, a exemplo da busca por visibilidade:

Enquanto as categorias mais usuais dos anos 70 (posseiros, arrendatários, parceiros e assalariados) refletiam a referência da lei, aquelas refletiam a nova dinâmica de lutas e expressavam identidades constituídas no próprio processo de crítica e enfrentamento das condições vigentes no meio rural (MEDEIROS, 2002, p. 164, grifos da autora).

Em relação à luta por garantia de direitos sobre a terra, também houve novas configurações. Além das reivindicações pelo direito de uso, até então predominante, foram incorporadas, pelos camponeses, novas concepções de direitos, nas quais "não era questionada a legalidade da propriedade da terra mas sim, principalmente, a sua legitimidade, uma vez que a apropriação não se justifica através de uma destinação produtiva" (MEDEIROS, 2002, p. 165). A questão da função social da terra, presente na Constituição, subsidiava esse horizonte.

As ocupações de terra constituíram o grande marco desse período. Através do Movimento dos Trabalhadores Rurais Sem Terra (MST), e sua nacionalização, elas se expandiram por todo o país no final dos anos 1980. Conforme aponta Medeiros (2002), o MST não representou apenas uma inovação nas formas de luta, mas extrapolou suas concepções e seu papel, 
ao defender que a demanda por terra não se limita à obtenção do lote, mas se estende a sua sustentação, à organização e aos subsídios para a produção dos assentados.

Todo esse processo não foi imune à repressão e à violência. Pelo contrário," o aumento na quantidade de ocupações e de volume de ocupantes foi concomitante ao crescimento da violência no campo" (MEDEIROS, 2002, p. 167). Dados da Comissão Pastoral da Terra mostram que nas décadas de 1980 e 1990 aconteceram 25 massacres no campo em oitos estados brasileiros. Entre eles, um na ocupação da Fazenda Santa Elina, em Corumbiara, estado de Rondônia, onde 20 trabalhadores desapareceram, 8 foram mortos - inclusive uma criança -, 200 presos, 350 feridos, além de dois policiais mortos. E outro em Eldorado dos Carajás, no Pará, onde 19 sem-terra foram mortos. Nos dois episódios, a Polícia Militar foi responsável pelas ações.

\section{INTERFACES DA VIOLÊNCIA NO CAMPO ONTEM E HOJE}

A partir desta revisão bibliográfica, percebe-se que a violência é característica basilar dos processos e das dinâmicas do campesinato no Brasil. Violência que não pode ser entendida nesse contexto apenas como manifestações físicas e concretas, mas a partir de decisões políticas e históricas. A exclusão da classe do campesinato, desde sua formação, é também uma forma de violência. Por mais que não tenha sido objeto da pesquisa, fica evidente que esse termo merece ser problematizado, pois se aplica a outras interpretações.

Diante do recorte temporal proposto, podemos observar que a violência esteve presente em todos os períodos estudados, apesar de apresentar formas e atores diferenciados em cada época. A questão da propriedade da terra, e a exclusão dela, é fator determinante nos conflitos, que desencadeiam episódios violentos. Durante os anos 1950 e 1990, a concentração de terras foi uma constante, o que mudou foi apenas a figura do proprietário, que de fazendeiro passou a ser a empresa multinacional ou o Estado, através dos projetos ditos de desenvolvimento, a exemplo das usinas hidrelétricas.

Destacamos também atores sociais que, durante o período analisado, influenciaram o campesinato brasileiro: o Partido Comunista Brasileiro, a Igreja Católica, o sindicalismo, movimentos sociais. Atualmente, à exceção do $\mathrm{PCB}$, os demais atores continuam em órbita desse segmento popular, mas não assumem mais papel determinante como aconteceu anteriormente. Entretanto, no âmbito político, vivenciamos o expoente da bancada ruralista 
no Legislativo, que conta com mais de 200 integrantes do Congresso Nacional, atuando em defesa dos interesses de grandes proprietários do setor.

Dados do Caderno de conflitos no campo apontam que os principais agentes de conflitos no estado da Bahia em 2016 foram: fazendeiros (29,41\%), empresários $(27 \%)$, mineradoras $(26,47 \%)$, grileiros $(09,80 \%)$ e governo $(06,86 \%)$. Se relacionarmos esses dados com as informações expostas nos itens acima, evidenciamos que as causas de conflitos no campo atualmente são bastante semelhantes às de décadas atrás. Portanto, a tendência da violência tende a se perpetuar, já que as estruturas do campesinato não foram alteradas profundamente.

Outro ponto a ser destacado é a influência dos contextos políticos na violência que acontece no campo. Durante as décadas estudadas, percebe-se que, quando o cenário político é modificado, imediatamente, reflete no campesinato. Se fizermos um link com o presente, a conjuntura política brasileira foi alterada em 2016, com mais um impeachment de um presidente, o que modificou o jogo de poder e também as políticas e as atuações relacionadas ao campo. Um estudo com foco nas interferências dessas atuações políticas no campesinato seria pertinente para avaliarmos a possível relação, ou não, com o aumento recente da violência no campo.

\section{CONSIDERAÇÕES FINAIS}

A violência nas áreas rurais tem suas raízes históricas na estrutura agrária brasileira, fortemente marcada pela hierarquização e pela desigualdade em relação ao acesso à terra. A violência sofrida pelas populações do campo é uma realidade no Brasil e constitui uma problemática alicerçada na centralização fundiária e na ausência de uma efetiva reforma agrária consistente, que deliberadamente foi negligenciada pelo Estado brasileiro.

Os grupos sociais que, no curso da trajetória dos conflitos no campo, reivindicaram direitos sociais, cidadania e acesso à terra foram marginalizados e secundarizados no processo das conquistas sociais do Brasil. A história oficial, quase sempre, tratou os grupos de contestação social nas áreas rurais como fanáticos, desordeiros ou invasores de terras, que se encontravam à margem das leis constituídas para proteger os poderes econômico e político estabelecidos em cada época da história nacional.

Por mais que seja invisibilizada, a violência atinge uma grande parcela da população. Os 71 assassinatos, registrados em 2017, não refletem a totalidade dessa violência no nosso país, mas expressam a barbaridade que ela pode significar. Só em 2017, a CPT contabilizou mais de 700.000 mil pessoas envolvidas em conflitos no campo. Esse quadro revela o quanto a sociedade 
brasileira precisa olhar para o que se passa nas áreas rurais. Os conflitos de terra e por terra no país ainda são mostrados e discutidos como aspectos presentes em uma suposta normalidade institucional, que não espanta, nem requer da sociedade decisões emergentes eficazes e consistentes.

Uma série de fatores relacionados a essa violência pode constituirse como objeto de estudo, a exemplo das suas causas, do público atingido, da impunidade e da institucionalização da violência. Este artigo, como mencionado anteriormente, não teve a intenção de esgotar as possibilidades a respeito do tema, mas de trazer um breve resgate histórico das raízes e dos altos índices da violência no campo para compreender o cenário atual. Sentimos falta, na bibliografia utilizada, da presença dos povos e das comunidades tradicionais, em sua diversidade, citados durante o recorte do estudo. Esse público representa hoje uma força expressiva do campesinato.

\section{STRUCTURAL ASPECTS OF VIOLENCE INTHE FIELD: A BIBLIOGRAPHIC REVIEW FROM THE BRAZILIAN CASE}

ABSTRACT: The history of the Brazilian peasantry is marked by brutal episodes of violence. From Canudos to Eldorado dos Carajás, violence has been constituted as a phenomenon present in the rural scope, reaching high rates in determined periods. In 2016, data showed an increase in rural violence in Brazil. This article aims to investigate the roots of this violence to understand the rise of statistics today. The study consists of a bibliographical review, based mainly on works by scholars such as José de Souza Martins (1990) and Leonildes Sérvulo de Medeiros (2002), with a major focus on the trajectory of social conflicts from the 1950s to the 1990s. The research results show that violence is the fruit of the very formation of the Brazilian peasantry and reproduces practically the same structures throughout Brazilian political, economic and social formation.

KEYwoRDS: Peasantry. Violence in the countryside. Struggle for land. Social exclusion. 


\section{ASPECTOS ESTRUCTURALES DE LA VIOLENCIA EN EL CAMPO: UNA REVISIÓN} BIBLIOGRÁFICA A PARTIR DEL CASO BRASILEÑO

RESUMEN: La historia del campesinado brasileño está marcada por episodios brutales de violencia. De Canudos a Eldorado dos Carajás, la violencia se ha constituido como fenómeno presente en el ámbito rural, alcanzando altos índices en períodos determinados. En 2016, datos revelaron un aumento de la violencia en el campo en Brasil. Este artículo, tiene como objetivo investigar las raíces de esta violencia para comprender la elevación de las estadísticas actualmente. El estudio, consiste en una revisión bibliográfica, basada, sobre todo, en obras de estudiosos como José de Souza Martins (1990) y Leonildes Sérvulo de Medeiros (2002), con foco mayor en la trayectoria de conflictos sociales de las décadas de 1950 a 1990. Los resultados de la investigación muestran que la violencia es fruto de la propia formación del campesinado brasileño y reproduce prácticamente las mismas estructuras a lo largo de la formación política, económica y social brasileña.

PalABras-Clave: Campesinado. Violencia en el campo. Lucha por la tierra. Exclusión social.

\section{NOTAS}

1 Dados obtidos na página Massacres do Campo da Comissão Pastoral da Terra (CPT) disponíveis no link: <https://www.cptnacional.org.br/mnc/index.php $>$.

2 Utilizam-se os mesmos conceitos de conflito e violência no campo do Caderno de conflitos.

\section{REFERÊNCIAS}

COMISSÃO PASTORAL DA TERRA. Conflitos no campo - Brasil 2016. Goiânia-GO, 2016. COMISSÃO PASTORAL DA TERRA. Massacres no campo. Disponível em: https://www. cptnacional.org.br/mnc/index.php. Acesso em: 13 nov. 2017, às $15 \mathrm{~h} 45$.

FROHLICH, E. R.; FROHLICH, C. Metodologia de pesquisa em estudos rurais investigando a partir de estudo de caso. In: CONTERATO, M. A.; RADOMSKY, G. F. W, SCHNEIDER, S. (Org.). Pesquisa em desenvolvimento rural: aportes teóricos e proposições metodológicas. Porto Alegre: Editora da UFRGS, 2014. v. 1.

HEREDIA, B; PALMEIRA, M; LEITE, S. P. Sociedade e economia do agronegócio no Brasil. Revista Brasileira de Ciências Sociais, v. 25, n. 74, 2010. Disponível em: http://campohoje. net.br/sites/default/files/acervo/revista_rbcs.PDF. Acesso em: 15 nov. 2017, às $12 \mathrm{~h} 32$.

MARTINS, J. S. Os camponeses e a política no Brasil. 4 ed. Petrópolis, RJ: Editora Vozes, 1990. v. 1. 
MEDEIROS, L. S. Os trabalhadores do campo e desencontros nas lutas por direitos. In: CHEVITARESE, André (Org.) O campesinato na História. Rio de Janeiro: Relume Dumará, 2002. Disponível em: http://w3.ufsm.br/gpet/files/Texto.pdf. Acesso em: 15 nov. 2016, às $18 \mathrm{~h} 08$.

Luta por reforma agrária no Brasil contemporâneo: entre continuidades e novas questões. In: GRISA, C.; SCHNEIDER, S. (Org.) Políticas públicas de desenvolvimento rural no Brasil. Porto Alegre: Editora UFGRS, 2015.

Juliana Maria Magalhães lopes Cerqueira: Mestranda do Programa de Pós-graduação em Extensão Rural da Universidade Federal do Vale do São Francisco (UNIVASF). Graduada em Comunicação Social - Jornalismo em Multimeios pela Universidade do Estado da Bahia (UNEB).

E-mail:.jmm.lopess@hotmail.com

Denes Dantas Vieira: Doutor em Ciências Sociais pela Universidade Federal do Rio Grande do Norte (UFRN). Professor do Programa de Pós-graduação em Extensão Rural da Universidade Federal do Vale do São Francisco (UNIVASF).

E-mail: denes.vieira@univast.edu.br 